\title{
Reflexiones sobre el diseño de políticas públicas en tiempos de (pos)pandemia: una aproximación a través de tópicos conceptuales
}

\section{Insights on the Design of Public Policies in Times of (Post)pandemic: An Approach through Conceptual Topics}

\author{
Mariana Laura LóPEZ \\ Facultad de Derecho \\ Universidad de Buenos Aires | Argentina \\ Contacto: lopezmarianalaura@gmail.com \\ Juan Cruz Margueliche \\ Facultad de Humanidades y Ciencias de la Educación \\ Universidad Nacional de La Plata | Argentina \\ Contacto: jcruzmargueliche@gmail.com
}

\section{Resumen}

Se propone la reflexión sobre el diseño de políticas públicas y de gestión estatal a partir de tópicos centrales enfocados al socialmente diverso ámbito urbano, en el marco de la COVID-19. Por un lado, analizamos categorías y conceptos filosóficos de utilidad para comprender y abordar las conflictividades territoriales y las desigualdades sociales que, aunque preexistentes, la pandemia acentuó o develó. Por otro lado, se busca construir herramientas conceptuales partiendo de que las formas de gestión se ponen en diálogo a la hora de diseñar políticas públicas. A partir de esto, el análisis de conceptos y categorías, tales como las representaciones espaciales, el habitar, las movilidades urbanas cotidianas, entre otras, buscan aportar perspectivas para el diseño de políticas públicas urbanas en el contexto de la medida excepcional de "Aislamiento social, preventivo y obligatorio" (ASPO), establecido en Argentina a causa de la pandemia de COVID-19. Se eligieron conceptos y categorías 
desarrolladas por pensadores como Heidegger e Ingold para pensarlas como herramientas que mejoren las condiciones de vida de las personas. Esta reflexión pretende la introducción de temas que consideramos pertinentes para el diseño y análisis de políticas públicas. Consideramos que en el diseño y la gestión de políticas públicas frecuentemente se parte de representaciones disociadas de las propias vivencias que los actores sociales tienen de su entorno. En este sentido, el trabajo se centrará en una discusión de corte conceptual generalista buscando estimular la reflexión y atención de las dimensiones que se discuten en el ejercicio de transferirlas a casos concretos.

Palabras clave: políticas públicas, representaciones sociales, habitar, movilidades urbanas, pandemia

\section{Abstract}

The proposal aimed to design public policies and state management for reflection from central topics focused on the socially diverse urban scope within the framework of the COVID-19. On the one hand, we analyze categories and philosophical concepts of utility to understand and address territorial conflicts and social inequalities that, although preexisted, the pandemic accentuated or unveiled. On the other hand, it seeks to build conceptual tools based on the management forms are dialogue when designing public policies. From this, the analysis of concepts and categories, such as spatial representations, dwelling, daily urban mobilities, among others, seek to provide perspectives for the design of urban public policies in the context of the exceptional measure of "Social Isolation, Preventive and Mandatory" (ASPO in Spanish), established in Argentina because of the Covid-19 pandemic. Concepts and categories developed by thinkers as Heidegger and Ingold were elected to think about them as tools that improve people's living conditions. This reflection intends to introduce topics that we consider relevant to the design and analysis of public policies within the (pos) pandemic framework from critical and descriptive reading. We believe that in the design and management of public policies, it is often part of dissociated representations of social actors' experiences in their environment. In this sense, the work will focus on a general conceptual court discussion seeking to stimulate the reflection and attention of the dimensions discussed in transferring them to specific cases.

Keywords: public policies, social representations, dwelling, urban mobilities, pandemic 


\section{Introducción}

La centralidad del tema se basa en la preocupación del diseño de las políticas públicas en el contexto de la pandemia ocasionada por el virus SARS-CoV-2. Se busca reflexionar acerca de las construcciones conceptuales en posibles escenarios de intervención con el fin de aportar una sistematización teórica de carácter exploratorio que indague en la realidad que nos agobia la contención e identificación de problemas sociales persistentes. Si bien la pandemia de COVID-19 abrió viejos y nuevos debates sobre las problemáticas sociales en las ciudades, la irrupción también obligó a abrir nuevos interrogantes con otros instrumentos y herramientas del diseño de políticas públicas ante la necesidad de acercarse a los problemas emergentes para enfrentar la pandemia.

La estructura del texto se enmarca en principio, en la reflexión de algunas categorías y conceptos para comprender y abordar el diseño de las políticas públicas en el contexto de conflictos territoriales recurrentes y desigualdades sociales prexistentes que la pandemia acentuó o develó. Para ello, realizaremos un recorte y selección de algunos temas que, a nuestro entender, permitirán repensar el diseño de políticas públicas enfocadas al ámbito urbano durante y a posteriori de la medida excepcional de Aislamiento Social, Preventivo y Obligatorio (ASPO) establecido en Argentina, a causa de la pandemia de COVID-19.

Entre los conceptos y categorías seleccionados destacamos las representaciones sociales del espacio, lugar, habitar y movilidad urbana cotidiana, entre otras, con el objetivo de avanzar en la formulación de políticas urbanas más allá de introducir solo la lectura de la pandemia. Se busca plantear alternativas conceptuales-metodológicas que abran una mirada integral al diseño de las políticas públicas y repensar las prácticas. Siguiendo a Tamayo Sáez (1997), la política pública se define a partir de aquellos objetivos, decisiones y acciones que un gobierno lleva a cabo con el fin de brindar solución a los problemas contextualizados, los que en momentos determinados, sea de incremento, crisis, coyuntura, se consideran prioritarios y son introducidos en la agenda estatal a instancias de las demandas ciudadanas. Este autor analiza la política pública como un proceso con diferentes etapas que van desde la identificación y definición de los problemas de carácter público hasta su ingreso en la agenda de gobierno, pasando por la enunciación de posibles alternativas para su solución, la toma de decisiones y el diseño o formulación de la política, la implementación y, finalmente, su evaluación. 
En la práctica, el desarrollo de las políticas públicas es dinámico y participan en él tanto actores estatales, como otros sectores de la sociedad "[...] configuran[do] campos de relaciones sociales, relaciones de poder que implican relaciones de fuerza en la producción instrumental y simbólica, al adoptar sucesivas tomas de posición y actuar en consecuencia, transformando la realidad" (Díaz, 1998: 78). En la presente reflexión se intenta introducir elementos teóricos que permitan iluminar el diseño de políticas públicas, orientando "de manera más o menos explicita, los conceptos y los modos a través de los cuales se ponen [estos] en relación, organizando y orientando la acción más o menos efectiva, confiriéndole sentido" (Chiara y Di Virgilio, 2017: 53).

En el transcurso de más de un año resulta innegable que la pandemia generó en los territorios consecuencias sanitarias, económicas, políticas y sociales, desnaturalizando situaciones tales como el acceso al mercado laboral, la caída de las condiciones socioeconómicas, la falta de acceso a la salud, a la vivienda, entre otras. Exacerbando las problemáticas que distintos grupos de habitantes venían sufriendo en sus contextos de emplazamiento de manera interna, particularmente en ciertos barrios populares y asimismo, de forma externa en cuanto a la accesibilidad y conectividad de su hábitat con los servicios e infraestructura de la ciudad. El ASPO fue una medida excepcional adoptada por el gobierno nacional argentino desde el 20 de marzo de 2020, con el fin de proteger la salud pública frente a la propagación del nuevo coronavirus; a través de su implementación se dispuso que todas las personas, residentes y no residentes, debían permanecer en sus domicilios habituales pudiendo realizar desplazamientos mínimos e indispensables para aprovisionamiento de alimentos, artículos de limpieza y medicamentos.

En relación con estas y otras medidas surgen las preguntas ¿Se incorpora en el diseño de las políticas públicas el debate de categorías y conceptos como el lugar habitado, las representaciones espaciales? ¿Se anticipan realmente los impactos y las consecuencias de éstos en el ámbito de la gestión? ¿Es posible hacerlo en medio del tránsito de problemas que ha generado la irrupción de la COVID-19? ¿O ante una situación así, solo hay tiempo para la casuística? Ante estos interrogantes creemos que más allá de la coyuntura y el estado actual de los espacios locales, los problemas que plantea la pandemia no solo radicarían en la falta de tiempo para una reconfiguración del diseño y gestión de la política en tiempos de pandemia, sino la ausencia de una tradición institucional previsora de este tipo de tra- 
bajos producto, en parte, por la falta de presupuesto e inversión; asimismo, por la falta de visión ante las variadas problemáticas de la planificación urbana a largo plazo. Y esto evidencia los problemas que se enfrentan en relación con el acceso y el derecho a la ciudad.

La referencia a la planificación implica que debemos hacer un paréntesis. La planificación urbana integral es una herramienta necesaria y compleja que requiere ponerse en diálogo con múltiples dimensiones, actores, metodologías y escalas. El proceso de planificación requiere abrirse a las múltiples miradas orientadas hacia una gobernanza territorial ampliada y crítica; partiendo del diseño explícito que describe su accionar sobre los objetivos que se propone proseguir. Sin embargo, tácitamente excluye a otras variables y dimensiones; por tanto, será preciso reconocer a priori que toda planificación tendrá siempre un doble carácter de inclusión - exclusión.

Debido a lo anterior, proponemos una secuencia organizativa que nos permita dar una lectura articulada a los temas propuestos. Para ello, en primer lugar, trabajaremos con categorías, como el lugar (Massey, 2012), la planificación y el diseño (Heidegger, 1994; Ingold, 2012) y la movilidad urbana cotidiana (Jirón, 2009; Jirón y Mansilla, 2013). En segunda instancia, consideramos dos representaciones espaciales relevantes en los ámbitos de gestión: la dicotomía centro y periferia y la dupla movilidad de las personas e inmovilidad de los espacios. Esta última instancia nos permite retomar los temas propuestos para desnaturalizar la mirada técnica sobre el espacio, buscando puntos de inflexión con la situación de la pandemia, con el fin de generar espacios de reflexión para abrir interrogantes y propuestas para (re)pensar el diseño de políticas públicas integrando conceptos y categorías que estimulen el ejercicio de transferencia a casos concretos de manera situada. El principal aporte consiste en el análisis de categorías conceptuales provenientes de diferentes filiaciones teóricas, buscando trasladarlos con un nuevo corpus, para abordar la problemática seleccionada.

\section{La representación del espacio}

Cuando hablamos de representación espacial nos referimos a los postulados promulgados en "La producción del espacio", Lefebvre (2013), quien lo identifica como 
espacio conceptualizado producido por los científicos, los planificadores, los urbanistas, técnicos e ingenieros sociales. Sin embargo, el interrogante que se plantea gira en torno a ¿cómo se comprenden y registran las vivencias y las representaciones de los actores sociales? En principio tenemos la distinción, por un lado, de los actores que diseñan las políticas públicas y, por el otro, los actores cuyas vivencias en la ciudad están ligadas a través de sus prácticas espaciales cotidianas. Esta distinción nos conduce a reconocer y buscar estrategias de relevamiento.

Para identificar a los gestores de políticas públicas tenemos que analizar las diferentes propuestas, sean diseños, programas, normativas, discursos, entre otros, así como los niveles de intervención de las políticas. Respecto a las vivencias de los habitantes se requiere un trabajo de campo abierto a metodologías cualitativas como la cartografía social, entrevistas, talleres de validación social, entre otras. Esto de ninguna manera desplaza a la incorporación de metodologías cuantitativas ya que, para abarcar universos complejos y extensos, la interpretación a través del relevamiento de datos es un paso importante. Por otra parte, consideramos que los postulados de Lefebvre (2013) nos permiten responder a esta interrogante no solo para contraponer los diferentes espacios que están en juego en los territorios de la vida cotidiana, sino también porque abren instancias de complementariedad y disputa entre los actores y sus diferentes espacios.

Baringo Ezquerra (2013) coincide con el análisis-síntesis de la clásica y vigente propuesta de Lefebvre para analizar la producción del espacio. Los principales términos explicativos propuestos por Lefebvre, son tres: la representación del espacio, el espacio de representación y las prácticas espaciales. Presentaremos los elementos centrales de cada categoría para diferenciar las prácticas espaciales a la luz del diseño de políticas públicas.

1. En las representaciones del espacio concebido, según Lefebvre se trata de un espacio abstracto que suele representarse en forma de mapas, planos técnicos, memorias, discursos y que es generalmente conceptualizado por los denominados "especialistas" y técnicos. Para el autor, el espacio dominante en las sociedades modernas está directamente atado a las relaciones de producción existentes en una sociedad y al orden en el que estas relaciones se imponen. En este sentido, el espacio está compuesto por signos, códigos y jergas específicas usadas y producidas por estos especialistas. Retomando esta categoría, para algunos gobiernos municipales la gestión del territorio nace desde "arriba", quedando muy poco margen para la 
participación social. O esta no forma parte de una política integral extensiva, dejando de lado las representaciones del espacio a las miradas externas de los territorios.

2. El espacio de representación o espacio vivido es el espacio del "debería ser", el cual es plenamente vivido "experimentado directamente por sus habitantes y usuarios a través de una compleja amalgama de símbolos e imágenes. Es un espacio que supera al espacio físico y material, es aquel donde la gente hace un uso simbólico de los objetos que lo componen. Este es también un espacio evasivo" (124), ya que el recurso de la imaginación actúa como dispositivo para cambiarlo y apropiarlo de maneras diferenciales. Por lo cual, Baringo Ezquerra sitúa a este espacio como un lugar dominado y experimentado de forma pasiva por las personas, siendo un "objeto de deseo" por parte de los ya mencionados "especialistas" que buscan permanentemente codificarlo, racionalizarlo y usurparlo; es decir, arrancarlo del universo social constitutivo propio de las comunidades para ponerlo en escena desde una lógica del espacio cartesiano, plano. Con lo cual, hablaríamos de la pérdida que genera la sensación de miedo, la anulación de nuevas formas de pensar y abordar el espacio, bajo la mirada de los técnicos. Estos espacios requieren relevamientos, es decir, un reconocimiento de sus potencialidades y de los dispositivos de reafirmación que van más allá de recorrer un barrio en un plano de manera esporádica. En esta unidad de análisis: el barrio debe decodificarse por medio de dispositivos de relevamientos pero que a su vez reconstituyan su historicidad, las dinámicas de los actores, las relaciones de escalas.

\section{Prácticas espaciales o espacio percibido, este es el espacio}

que integra las relaciones sociales de producción y reproducción, en especial la división del trabajo, la interacción entre gente de diferentes grupos de edad y género, la procreación biológica de la familia y la provisión de la futura fuerza de trabajo. Incluye la producción material de las necesidades de la vida cotidiana (casas, [equipamientos en las] ciudades, carreteras), asimismo el conocimiento acumulado por el que las sociedades transforman su ambiente construido. (Baringo Ezquerra, 2013: 124)

Aquí hablamos de un espacio que está directamente relacionado con la percepción que la gente tiene de él con respecto a su uso cotidiano: "sus rutas de paseo, los lugares de encuentro" (124). Este tercer espacio quizá logra condensar las relaciones con los dos espacios anteriores. Y es a partir de él que podemos retomar otros tópicos, 
conceptos y categorías, como las movilidades y el habitar. La vinculación entre estas tres esferas suele ser conflictiva, es el propio Lefebvre quien destaca las relaciones especialmente beligerantes entre las representaciones del espacio, "el espacio de los burócratas y los técnicos, frente a los espacios de representación, configurando el espacio vivido y apropiado directamente por los actores sociales, y al espacio percibido. Esferas articuladas en una dialéctica profundamente marcada por la política, las ideologías" (Baringo Ezquerra, 2013: 125) y las relaciones de poder basadas en su carácter asimétrico. En este sentido, resulta muchas veces difícil encontrar en los diseños de las políticas públicas la recuperación de esta sociabilidad en la concepción anterior del espacio social, como "[...] si la simplicidad del esquema producido sobre el papel o en la maqueta no estuviera calculada nunca para soportar el peso de las vidas relacionadas que van a desplegar ahí todas sus iniciativas" (Delgado, 2004: 7).

\section{Los tópicos de análisis para el diseño de las políticas públicas}

En primer lugar, antes de iniciar los tópicos seleccionados en este apartado, nos parece interesante dedicar una reflexión a dos miradas de filiaciones teóricas y conceptuales diferentes y temporalmente distintas para el desarrollo del planteamiento que estamos proponiendo sobre la idea del habitar, las que requieren ser contempladas para comprender las sinergias sociales en los territorios que forman parte de la experiencia de las personas y sus comunidades. La primera propuesta convergente es la idea de habitar y construir que Heidegger (1994) propuso en el siglo pasado. La segunda propuesta es la de Ingold (2012), quien nos acerca la idea de ambiente y diseño. Ambas miradas coinciden en el papel de los habitantes como protagonistas en la génesis de las políticas, considerándolos sujetos necesariamente convocantes a la hora de planificar.

Para Heiddeger (1994) el problema era que se estaba pensando el habitar y el construir como dos actividades diferentes. Así, se permite interpelar el significado de construir a través de un ejercicio etimológico, remitiéndose al alto alemán antiguo, donde construir: "buan"”, cuyo significado es habitar. En ese mismo sentido

\footnotetext{
1 El significado propio del verbo es "bauen" (construir).
} 
plantea que las personas "son" en la medida en que "habitan". El inconveniente señalado por este autor es, por un lado, que el habitar no se vivencia como algo inherente a la sociedad o como un rasgo fundamental del ser del hombre y, por otro lado, que la esencia del construir es, en definitiva, el dejar habitar y en ese sentido solo si somos capaces de habitar podremos construir.

En cambio, para Ingold habitar forma parte de la percepción del ambiente más alla de la naturaleza y la cultura. A diferencia del construir, el habitar es un proceso fundamentalmente temporal que posibilita una acción continuista de la realidad. En este sentido, Ingold invita a reflexionar sobre la acción del diseñar. Su preocupación se centra en el diseño de los ambientes para el despliegue de la vida, entendiendo que diseñar es darle forma al futuro del mundo en que vivimos. Su sustentabilidad no tendrá que ver con proyecciones y objetivos, sino más bien con mantener la vida andando, fluyendo. Presupone que la vida social humana no está aislada en un plano separado, sino que es parte integral de un proceso continuo, compuesto por la interacción de diversos seres humanos y no humanos y sus mutuos enmarañamientos (Ingold, 2012). Dentro de esas marañas de senderos o fibras entrelazadas, continuamente deshilachándose e hilándose los organismos crecen y proceden a lo largo de las líneas de sus relaciones (Ingold, 2012).

En definitiva, si lo que finalmente se plasma en el espacio diseñado no son las presencias, las interacciones, las conflictividades, no se plasman tampoco las ausencias (Delgado, 2004). Esta distinción nos es útil para pensar que el espacio es practicado, a diferencia del espacio concebido o diseñado, se reconoce la heterogeneidad de los actores y sus acciones orientadas por las múltiples negociaciones, discusiones, innovaciones, pérdidas, una miríada de acciones (2004). La ciudad como espacio se convierte en un escenario donde se negocia en una trama de conflictividades y consensos, sobre la que uno se pierde y da con el camino, espera, piensa, encuentra su refugio o su perdición, lucha, muere y renace infinitas veces (2004). Delgado logra una mediación o síntesis más o menos imparcial en tanto que, "[...] no hay más remedio que aceptar someterse a las miradas y a las iniciativas imprevistas de los otros" (Delgado, 2004: 8).

Otro tópico que introducimos en el diseño de políticas es el de las movilidades. Para Jirón (2009) y Jirón y Mansilla (2013) podemos comprender el acceso a la ciudad a través de reconocer el rol de la movilidad y la accesibilidad. Los autores interrogan la movilidad urbana cotidiana encontrando múltiples barreras de accesibilidad que los diferentes viajeros y viajeras encuentran diariamente en sus trayectos 
por la ciudad, los cuales van configurando lo que denominan como "espesura" en la experiencia del tiempo - espacio, una metáfora de la multiplicidad de barreras que se van constituyendo e impiden la accesibilidad por las prácticas de movilidad en la vida cotidiana (Jirón y Mansilla, 2013: 54). La discusión que proponen los autores tiene carácter epistemológico a través de dos giros: el espacial y el de las movilidades. El giro espacial es útil para abordar el estudio del espacio y de la ciudad producto de las prácticas sociales materiales y subjetivas. En cambio, el giro de la movilidad propone discutir la necesidad de integrar una noción espacio- temporal sobre la ciudad, de carácter relacional integrando las formas en que se desenvuelven las prácticas móviles de la sociedad (58). La mayoría de los estudios sobre las movilidades en el espacio urbano lo hacen a través del tema del transporte y las infraestructuras, pero poco se ha estudiado la movilidad cotidiana a través de las condiciones y experiencias de los desplazamientos de las personas.

Para comprender los numerosos problemas que atraviesan las personas en los diferentes sectores territoriales a lo largo de sus prácticas cotidianas es necesario aproximarse a los tipos de barreras que experimentan: la multiplicidad de obstáculos que enfrentan cotidianamente, comprendiendo los ritmos, rutinas y hábitos propios de la vida diaria que, como mencionan los autores, dan una "espesura" a la accesibilidad. Así también se incorporan nuevas metodologías de análisis, entre ellas, los métodos móviles, como la etnografía urbana y la técnica del sombreo, acompañando a personas en sus trayectos diarios. Esto se asocia con la metodología multi-sitio, donde nuestro objeto de estudio se abre a la multiplicidad de combinaciones y escalas más allá de límites formales y el concepto de "espesura" permite dar cuenta de la densidad de barreras de accesibilidad que adquiere la movilidad en la vida cotidiana. Asimismo, la movilidad resulta ser algo más que viajar de un punto a otro, y por ello su análisis debe contemplar múltiples dimensiones, señaladamente tres, la manera en que se va secuenciando a lo largo del viaje, las interacciones y combinaciones, previstas o no, y la multiescalaridad de los destinos y orígenes. En tal sentido, "La espesura de la accesibilidad" dará cuenta de una combinación de barreras que implica mucho más que una simple sumatoria en un momento del viaje (Jirón y Mansilla, 2013).

Resulta importante incorporar la mirada en las movilidades urbanas cotidianas a la hora de pensar el diseño de una política pública, porque nos permitirá poner la atención ya no solo en el lugar donde se pretende realizar la intervención, en tanto 
lugar practicado, sino en las relaciones entre los más disímbolos lugares y sus barreras, en las redes que conforman y se conforman entre los actores a partir de sus prácticas cotidianas. Así, centrar la mirada en relación con las prácticas (De Certeau, 2000) nos permitirá observar las operaciones y las movilidades que orientan la conformación del espacio en el cual se pretende intervenir.

Por último, traemos la propuesta teórica y metodológica de Massey (2012) con la categoría de lugar. Para esta geógrafa, todo lugar no radica en una historia interna y aislada, sino que se ha construido a partir de una constelación determinada de relaciones sociales encontrándose y entretejiéndose en un sitio particular. Cada lugar es un encuentro de relaciones, procesos y flujos. Los lugares no debemos verlos y abordarlos solo como áreas contenidas dentro de límites cerrados, sino como recortes territoriales articulados en redes de relaciones e interpretaciones sociales. Es decir, la autora nos invita a identificar y reconocer el sentido extrovertido del lugar y de la conciencia de sus vínculos extra e intra escalar, local-global. Si pensamos en la búsqueda de una estrategia por parte de aquel que tiene a su cargo el diseño de políticas públicas para el despliegue de acciones en el territorio, la perspectiva de De Certeau (2000) nos ayuda a comprender el valor de centrar la mirada en relación con las prácticas y observar las movilidades en el espacio donde ocurre la intervención. Bueno sería aprender a seguir los trazos de sus habitantes para poder leer el "texto urbano" (2000) que ellos inscriben en él, lo que nos proporcionará una ventaja para poder conocer las redes que se despliegan, las estrategias de vida, las maneras de hacer, las trayectorias y las movilidades.

\section{(Re)pensar los conceptos anteriores en la gestión de políticas públicas en tiempos de (pos)pandemia}

Una vez presentados los diferentes tópicos en el apartado anterior conviene realizar algunas aclaraciones en este apartado metodológico. En primer lugar, asentamos que los y las diferentes autoras citadas no trabajan en el mismo campo teórico, ni en temporalidades comunes. Esto no anula la posibilidad de ponerlas en diálogo para encontrar espacios comunes; en estos emergen los interrogantes ¿qué pasa con las distancias y diferencias conceptuales, geográficas y temporales de sus producciones? Para ello se necesita buscar una problemática e interrogantes que permitan llevar 
adelante un emprendimiento metodológico para facilitar el trabajo indagatorio. Por otro lado, se deben retomar las nociones buscando proponer algún tipo de articulación entre los conceptos propuestos para el debate y la instancia de reflexión.

Recordemos que la discusión que aquí se presenta a partir de estos conceptos nace de la situación suscitada por la COVID-19 y no busca centrarse en un estudio de caso en particular. Nos proponemos partir de una perspectiva general para avanzar en la discusión conceptual sin un correlato en una unidad de análisis específico, considerando central el valor universal de los conceptos. Por ello podría parecerle al lector o lectora la sensación de ciertas desconexiones entre las categorías trabajadas y el territorio. Para trascender esto, trataremos de avanzar con una mirada relacional entre los conceptos, la gestión y la situación de la COVID-19 contextualizada en Argentina. Aquí surgen dos interrogantes: ¿Qué pueden aportar aquellos conceptos a la discusión planteada por COVID-19? ¿Y en qué medida el futuro escenario (pos)pandemia dejará lugar a estos conceptos en el plano del diseño de políticas públicas? Como hemos expresado, algunas concepciones aún perduran en los imaginarios urbanos y por ende en los discursos. Esta relación entre imaginarios y discursos no es una asociación inocua, sino que opera y se despliega en instancias de políticas urbanas. Si bien son muchas las representaciones espaciales que atraviesan la gestión política de las ciudades, nos proponemos debatir al menos dos de ellas, las cuales nos servirán de base para introducir los conceptos en el marco del diseño de políticas urbanas.

En la visión territorial de la gestión política de los municipios consideramos que pervive de manera constante la imagen urbana de carácter fragmentado y fuertemente atravesado por imaginarios urbanos anclados en instancias históricas pasadas, que se fijan en torno a las decisiones de la planificación del espacio urbano en la actualidad. Se requiere la realización de un ejercicio de debate situado acerca de las lógicas de organización y representación política del espacio que han perdurado a lo largo del tiempo. Hablamos de la conceptualización y también de la gestión de los espacios como centros y periferias, de las movilidades en torno a los flujos y de la espacialidad desde los fijos.

Por un lado, la centralidad y periferia de la ciudad es un producto que no solo nace de las políticas, sino también de los procesos y representaciones hegemónicas históricas sobre los espacios. En la relación centro y periferia los imaginarios urbanos cobran fuertes registros que se expresan a través de correlatos espaciales. Esta 
distinción tiene cierto grado de arbitrariedad y su operatividad en el tiempo, ya que hacia adentro, cada territorio adopta su propia configuración temporal de centralidad o periferia; es decir, no hablamos de categorías ahistóricas e inmutables.

El trabajo de campo realizado por Segura (2015) en la periferia de la ciudad de La Plata, provincia de Buenos Aires, nos permite poner en juego las reflexiones anteriores. Este autor encuentra en la periferia de la ciudad otra configuración de centro y periferia, en un mismo barrio. La contemplación dicotómica del centro y la periferia nos arroja una mirada anclada en un tiempo inmóvil y carente de una propuesta de comprensión de otros procesos configurativos de los propios espacios. A partir de Segura (2015), en el barrio se logra identificar el despliegue de relaciones sociales desarrolladas en ese espacio, las que determinan nuevas configuraciones sujetas a la condición diferencial de sus habitantes con relación, por ejemplo, a la tenencia de la tierra, lo que explicita una de las distinciones de centralidad entre los propietarios y, en la periferia, "los intrusos”. Es decir, la contemplación dicotómica centro y periferia nos arroja una mirada anclada en un tiempo inmóvil y carente de una propuesta de comprensión de otros procesos configurativos de los propios espacios. Es allí donde la escala también es un recurso metodológico para repensar esas espacialidades. Por un lado, porque generalmente se piensa a esta dicotomía en un sentido de macro escala. Y por otro lado, porque esta supuesta dicotomía no contempla instancias relacionales. Segura (2015) sostiene que entre este tipo de espacios, independientemente de que existan diferencias y distancias socioespaciales, también existen y se configuran tramas relacionales; sean alianzas, conflictos, $\mathrm{u}$ otras formas. Lo cierto es que sobre estas estructuras perdurables y constantes se sustentan políticas diferenciales expresadas en obras, inversiones, partidas presupuestarias, entre otras formas de intervención en los espacios.

Por medio de la identificación de centralidades conflictivas donde convergen e interactúan actores sociales desiguales, así como los circuitos segregados en los modos específicos de conectar residencia, vecindad, trabajo, educación y ocio [se] busca problematizar los modos de comprender, los procesos de fragmentación social y espacial. Al respecto [se] sostiene que la fragmentación se refiere no solo a separación y distancia entre grupos sociales, sino también a los modos en que se establecen las interacciones y se tramitan los encuentros entre ellos. (Segura, 2018: 156) 
En el fragmento anterior podemos entender que los conflictos se suscitan más allá de la localización en el centro o la periferia, sentando sus bases en las relaciones y discontinuidades en el contexto de vida próximo y en el entorno urbano más amplio. Por lo que, al momento de plantear las alternativas que configuran el diseño de una política pública con abordaje territorial, no debe ignorarse como se experimenta la movilidad del barrio o en el territorio que se pretende abordar. Pensar en cómo se articulan las prácticas culturales y las dinámicas territoriales, su identificación e inclusión, permitirá identificar cuáles son los estigmas que limitan las movilidades $\mathrm{y}$ las interacciones sociales.

En este sentido, la política pública tiene el rol fundamental no solo de mejorar las condiciones de vida de los habitantes, sino también propiciar el reconocimiento social asociado con el habitar, en el sentido heideggeriano, a partir de identificar el estigma asociado con el hecho de habitar en determinado barrio o localización en determinados barrios con distintas localizaciones, y asimismo, el difuminar los límites o fronteras que distinguen el adentro y el afuera. Podríamos pensar, por ejemplo, en la construcción de espacios públicos con oficinas de servicios, centros para el desarrollo de actividades deportivas y culturales que inviten a la interacción social y la movilidad, independientemente de la pertenencia territorial. Estas acciones tienen el objetivo de disminuir los efectos de la segregación territorial, articulándose con las dinámicas y fuerzas sociales presentes en los barrios. No obstante, la construcción de estos espacios intermedios podría posibilitar el ensamble entre el barrio y lo que se encuentra fuera de él. También deberían acompañarse de un profundo estudio de las interacciones sociales, de las normas culturales de ambos espacios, asimismo, de estrategias que permitan el complejo abordaje de los problemas estructurales que coadyuvan a la profundización del distanciamiento social y los estigmas territoriales.

Considerando lo anterior, se propone cuestionar la idea de la ciudad como un locus fijo. Generalmente la mirada de la gestión, y muchas veces de los y las investigadoras, es pensar los barrios como espacios cerrados, cuyos límites coinciden de manera natural con los planos catastrales. La mirada confinada o la supuesta pasividad de sus habitantes ha llegado a justificar la implementación de acciones y políticas focalizadas que subestiman el impacto territorial de sus movilidades. Esto es lo que ocurrió a partir de la irrupción del COVID-19 en algunos barrios de la periferia o que se encontraban en condiciones de periferia en nuestro país. Cuando hablamos 
de barrios lo hacemos en sentido abstracto derivado de casos donde el Estado y otros actores intervinieron y gestionaron la cuarentena.

De manera representativa destacamos el caso de Villa Azul en la localidad de Quilmes, Provincia de Buenos Aires. Villa Azul resulta un caso paradigmático de amplia difusión en los medios de comunicación a nivel nacional frente a la ocurrencia del brote de COVID- 19. A partir de las características de vulnerabilidad social en el barrio se dificultó cumplir con el aislamiento domiciliario y otras medidas de prevención. Localmente se implementó una estrategia de aislamiento comunitario como respuesta sanitaria. Las comunidades barriales desarrollaron una metodología principal con el fin de contener el virus, y entre otras cuestiones, consideraron la identificación de los límites del barrio y su cierre por parte de las fuerzas de seguridad. Los habitantes del barrio tuvieron permitida la circulación al interior, asumiendo que todos los habitantes eran casos sospechosos de COVID-19, o tenían contactos estrechos con algún caso positivo. Con el fin de asegurar su aislamiento para contener la propagación, realizaron una activa búsqueda de casos sospechosos de COVID-19 adoptando una estrategia comunitaria para la vigilancia de la epidemia, la prevención y las medidas de control dentro del barrio.

En este contexto, el lugar y las movilidades colisionaron al generarse una política de clausura, de la desconexión del barrio con las diferentes redes extrovertidas que sus habitantes habían construido a lo largo de sus actividades cotidianas. Se hizo patente que las personas se mueven y desplazan diferencialmente y son ellas en el territorio las que configuran la ciudad. Cabe preguntarse ¿cómo llevar adelante prácticas de confinamiento de las personas ante sus necesidades inmediatas, algunas de estas fuera del barrio? Salir del barrio es (ex)ponerse en contacto con la vida, una vida que fluye más allá de la unidad espacial del barrio. Los confinamientos comunitarios en Argentina para algunos barrios, se implementaron bajo la premura de evitar que el virus y por tanto las personas se movilizaran. Estos confinamientos con lemas promulgados y difundidos ampliamente por los gobiernos y medios de comunicación, como "Quédate en casa", para evitar las movilidades de las personas y con ello la propagación del virus, requerían diferentes estrategias no solo por la situación socioeconómica de los habitantes, sino por el contexto de emplazamiento de los barrios. Ese pedido de inmovilidad desnaturalizó las condiciones de emplazamientos de los barrios desconectados de las tramas urbanas, situación que afectó las estrategias de los habitantes para sostener el aislamiento. Nos referimos al acceso del 
mercado laboral en condiciones de informalidad, a la asistencia médica, al sector de servicios y al consumo, entre otros.

[E]l centro de la ciudad no solo constituye [...] un paisaje habitual para personas que viven en sus proximidades, sino que también forma parte de las trayectorias cotidianas de la mayoría de los habitantes de los barrios cerrados y de los asentamientos informales. Sin embargo, a diferencia de la experiencia cotidiana de los habitantes de Barrio Norte, acceder al centro para estas personas supone suprimir (en condiciones desiguales y con medios diferentes) significativas distancias (Segura, 2018: 164).

En este sentido, y en relación con la cita anterior la irrupción de COVID-19 vino a profundizar las desigualdades y dificultades de acceso a las centralidades, siendo estas las más y mejores dotadas de servicios tanto públicos como privados. Por ello, poner la mirada en la escala barrial, implica el despliegue de políticas sociales y sanitarias en los barrios populares donde resulta difícil cumplir con las medidas de aislamiento domiciliario y las medidas de prevención como el distanciamiento social, la ventilación de los ambientes o la higiene de manos. Lo anterior, tomando en cuenta la vulnerabilidad de la población, donde los déficits habitacionales y el hacinamiento en muchos hogares han puesto a los gobiernos a repensar formas de abordaje para contener el virus, siendo una de las estrategias llevadas adelante la implementación del aislamiento comunitario como respuesta sanitaria al brote. Es aquí donde la dimensión espacial debe ser analizada tomando en cuenta las movilidades de las personas, como también para construir herramientas para abordar la unidad de análisis: el barrio.

La tarea de planificar, considerando la noción de habitar de Heidegger (1994) y el diseño ambiental según Ingold (2012) en la intervención de los territorios, nos convoca a reflexionar acerca de la forma en que las políticas públicas "bajan al territorio". Haciendo efectivo su despliegue y evidenciado en qué medida cierran o profundizan la brecha entre el ambiente experimentado y el ambiente proyectado, como una forma de poner en diálogo la mirada de los técnicos y al mismo tiempo recuperar la sabiduría, vivencias y prácticas de los habitantes del lugar que se pretende intervenir. Lo que en ningún caso implicará suprimir la labor del que planifica, sino que se busca la vinculación con la mirada y los sentires de los actores involucrados en esos entornos que se pretende modificar. 
En otro sentido, si pensamos en el habitar como una manera de ser y permanecer que define nuestra propia existencia, es preciso también centrar la mirada en el devenir de ese movimiento; es decir, en las actividades humanas que delinean la construcción del espacio practicado y las trayectorias de aquellos que, a través del desarrollo de su propia supervivencia se mueven conectando permanentemente el adentro y el afuera del territorio que habitan. Por otra parte, si pensamos cómo se articulan las prácticas culturales y las dinámicas territoriales, esto nos permitirá identificar cuáles son las dimensiones que limitan las movilidades y las interacciones sociales que aumentan la "espesura" del acceso a la ciudad. En este sentido, el objetivo de la política pública al realizar un abordaje territorial debería también estar concentrado en mejorar las condiciones de vida de los habitantes a fin de atemperar el estigma asociado al hecho de habitar en determinado barrio o localización, y a disfumar los límites o fronteras que distinguen el adentro y el afuera.

De este modo, afirmamos que el diseño de las políticas públicas surge de la relación entre los diferentes actores y, por tanto, no se encuentran completamente estructuradas por arreglos institucionales formales. Asimismo, debemos tener en cuenta que, en el ámbito local, debido a la proximidad entre el gobierno municipal y la sociedad, se multiplican los agentes sociales involucrados en la toma de decisión e implementación de políticas (Díaz de Landa y Permigiani, 1997). Debido a esta aproximación es importante resaltar la caracterización que se realiza de la política pública como un proceso social complejo (Díaz, 1998), que no transcurre en forma lineal y además, cabe agregar que se entrecruzan diferentes posiciones de los actores fundamentadas en valores y racionalidades distintas de la política, la técnica, la burocrática y de la población, siguiendo a Lapalma (2001).

A partir de nuestra reflexión se pretende estimular el debate sobre el diseño de políticas públicas inclusivas que acompañen el mejoramiento del hábitat en el que las personas residen, fortaleciendo al mismo tiempo el sentido de comunidad y la identidad colectiva. Sostenemos que el análisis del diseño de las políticas siempre será una instancia valiosa, independientemente del modelo de elaboración del que se valga el planificador para orientar las decisiones. El acuerdo general sobre la concepción de elaboración de las políticas es un tema abierto que ha generado dos corrientes principales de análisis. Por un lado, el racionalismo y por el otro lado, el incrementalismo (Tamayo Sáez, 1997). La diferencia fundamental entre ambas corrientes se basa en la importancia que conceden al análisis de políticas para influir y mejorar la elaboración 
de estas. Para los racionalistas, mediante el análisis es posible que las decisiones públicas se asemejen a las decisiones de ingenieros, industriales, con decisiones cuantificables, operativas, guiadas por criterios de eficacia en la consecución de los objetivos y eficiencia económica, preocupándose no sólo de qué hacer, sino también de cómo hacerlo. Por su parte, los incrementalistas abundan en el carácter elusivo, complejo, fragmentado y a veces incomprensible de los procesos sociales sobre los que las políticas públicas intentan influir, de modo que el análisis de políticas poco puede hacer para ordenar el cambio en presencia de factores como las relaciones entre los distintos niveles de gobierno, la divergencia de intereses, la inexistencia de objetivos claros y compatibles sobre qué debe hacerse, las presiones de individuos, grupos y empresas. Vale tanto el ser racionales como el incrementalismo lógico, cuando sea oportuno (Tamayo Sáez, 1997). Pensando en las ventajas de ampliar la caja de herramientas través de los conceptos y categorías presentadas, así como las perspectivas metodológicas propuestas, alcanzaremos la conceptualización de la gestión urbana (Chiara y Di Virgilio, 2017) en las prácticas que construyen los espacios estudiados y se abrirá la puerta a un conocimiento mayor y profundo de cuáles son las condiciones que determinan las interacciones sociales, con lo cual podremos alcanzar una comprensión mayor de la experiencia del vivir de los propios habitantes.

\section{Reflexiones finales}

El trabajo realizó una lectura a través de conceptos y categorías socioespaciales para al análisis del diseño de políticas públicas, tratando de utilizarlas para la evaluación y reflexión de medidas preventivas asumidas en el contexto de una pandemia, esto es, en forma coyuntural y urgente, como también en la pospandemia. El escenario actual de pandemia nos interpela a repensar y a interrogarnos EN cuanto a la emergencia de una planificación que nos aproxime a adaptarnos y a mitigar los impactos de la COVID-19. Asimismo a reconocer la diversidad de situaciones de desigualdad socioespacial preexistentes a la pandemia y pospandemia. Para ambas decisiones se necesitan tanto perspectivas teórico-conceptuales, como metodológicas. No hablamos de un fenómeno que se pueda nutrir de la casuística para enfrentarlo, sino que se requiere repensar cómo ha estado gestionándose en el espacio urbano para construir sobre las realidades materiales y las representaciones sociales las nuevas formas 
de diseño de políticas públicas. Ya que, independientemente de que se logre controlar y contener la pandemia, muchos problemas persistirán y se requerirán acciones concretas. Algunas serán políticas de carácter continuista, mientras que otras serán producto de nuevos campos emergentes del diseño y la intervención. La interpelación no solo se encuentra en las categorías analizadas, sino en los debates asociados a la planificación y al diseño urbano.

Por tanto, la realidad demanda que la intervención que realice el Estado se ejecute en nuestras ciudades o barrios a partir de instancias de co-construcción con todos los actores. El que prevalezca la tarea del planificador a partir de lo conocido o lo inmediatamente visible, desde una mirada totalizadora, homogeneizadora y uniforme de los territorios nos impedirá enriquecernos con los saberes y sentires de los habitantes del lugar, quienes transitan e intervienen en su cotidianeidad en lo que para ellos representa el espacio vivido, concebido, percibido y sus prácticas espaciales (Lefebvre, 2013).

De este modo, creemos que el diseño de las políticas públicas surge de la relación entre los diferentes actores y, por lo tanto, no se encuentran completamente estructuradas por arreglos institucionales formales. Asimismo, debemos tener en cuenta que, en el ámbito local, debido a la proximidad entre el gobierno municipal y la sociedad, se multiplican los agentes sociales involucrados en la toma de decisión e implementación de políticas (Díaz de Landa y Permigiani, 1997). De esta definición es importante resaltar la caracterización de la política pública como un proceso social complejo (Diaz, 1998), el que no transcurre en forma lineal y, además, agregar que se entrecruzan diferentes posiciones de los actores fundamentadas en valores y en racionalidades distintas las que, siguiendo a Lapalma (2001), son: la política, la técnica, la burocrática y la de la población.

Estas reflexiones propuestas por las y los diferentes autores en este trabajo forman parte de eslabones del diseño de las políticas públicas surgidas por la pandemia. Y que no deben convertirse en categorías estáticas y vectoriales de dichas políticas, sino que requieren ser interpeladas con los diferentes territorios para iniciar un diálogo "pendular" entre el campo teórico y los casos de estudio. Lo cierto es que muchas intervenciones a través de políticas públicas se tratan en planos muy abstractos y en el camino hacia la materialidad quedan muy distanciadas de los problemas de las comunidades. No obstante, la pandemia no permite margen de error, ya que las consecuencias son inmediatas. Por lo cual somos conscientes que los conceptos aquí 
discutidos tienen poco espacio de desarrollo y éxito en plena pandemia. Pero a partir del transcurso y la pos pandemia podemos considerar críticamente dichos conceptos en el contexto de una planificación de políticas públicas de carácter sostenible en el tiempo, más allá de los períodos gubernamentales.

A partir de nuestras reflexiones en este trabajo también se pretendió estimular el debate sobre diseño de políticas públicas inclusivas que acompañen el mejoramiento del hábitat en el que las personas residen, que al mismo tiempo fortalezca el sentido de comunidad y la identidad colectiva. Y en ese sentido, sostenemos la idea de que analizar el diseño de las políticas siempre es una instancia valiosa, independientemente del modelo de elaboración del cual el planificador se valga para orientar la decisión. Así tanto vale ser racionales cuando sea posible y utilizar el incrementalismo lógico cuando sea oportuno (Tamayo Sáez, 1997).

Para evitar llevar adelante políticas de confinamiento comunitario, las que consideramos insuficientes, se debe pensar en ciudades más integradas e igualitarias que permitan superar el carácter fragmentario y de enclaves (ricos y pobres) de las planificaciones que colonizan las cartografías de nuestras ciudades. Si pensamos en las ventajas de ampliar la caja de herramientas través de los tópicos presentados y las perspectivas metodológicas propuestas, conceptualizando la gestión (Chiara y Di Virgilio, 2017) y nos concentramos en las prácticas que construyen los espacios que se pretenden indagar, se abrirá la puerta a un conocimiento mayor y profundo de cuáles son las condiciones que determinan las interacciones sociales y podremos alcanzar una comprensión mayor de la experiencia de vivir de los propios habitantes.

Resulta indudable que la COVID-19 deja muchas experiencias e interrogantes que deberán ser materia de análisis al momento de la evaluación de las políticas públicas implementadas. Pero más allá de eso, y mientras continuamos atravesando la pandemia, podemos proponernos encontrar una mediación entre la representación de los técnicos y las propias vivencias y representaciones de los actores sociales que enriquezca el diseño de políticas públicas para el futuro.

\section{Referencias bibliográficas}

BARINGo EzQuerra, David. (2013). "La tesis de la producción del espacio en Henri Lefebvre y sus críticos: un enfoque a tomar en consideración”. Quid 16, (3), 119-135. https:// publicaciones.sociales.uba.ar/index.php/quid16/article/view/1133 
Chiara, Magdalena; Di VirgiLio, Mercedes. (2017). “Conceptualizando la gestión social”. En Magdalena Chiara y Mercedes Di Virgilio (Org.), Gestión de la política social. Conceptos $y$ herramientas (pp. 53-86). Prometeo-UnGs.

De Certeau, Michael. (2000). La invención de lo cotidiano. ITeso.

Delgado, Manuel. (2004). "De la ciudad concebida a la ciudad practicada". Archipiélago. Cuadernos de crítica de la cultura, (62), 7-12.

DíAz, Cristina. (1998). "El ciclo de las políticas públicas locales. Notas para su abordaje y reconstrucción”. En Juan Carlos Venesia (Coord.), Políticas Públicas y desarrollo local (pp. 67-107). Instituto de Desarrollo Regional; Centro de Estudios Interdisciplinarios; FLACso.

Díaz de Landa, Martha; Parmigiani, Consuelo. (1997). "Redes de influencia política, poder y desarrollo local”. En Daniel García Delgado (Comp.), Hacia un nuevo modelo de gestión local. Municipio y Sociedad Civil en Argentina (pp. 59-72). Universidad de Buenos Aires; Universidad Católica de Córdoba; FLACso.

Heidegger, Martín. (1994 [1951]). “Construir, habitar, pensar”. En Conferencias y artículos (pp. 127-142). Ediciones del Serbal.

InGOLD, Tim. (2012). Ambientes para la vida. Conversaciones sobre humanidad, conocimiento y antropología. Ediciones Trilce.

Jirón, Paola. (2009). "Prácticas de movilidad cotidiana urbana: Un Análisis para revelar desigualdades en la ciudad”. En Manuel Tironi Rodó y Fernando Pérez Oyarzun (Eds.), SCL. Espacios, Prácticas y Cultura Urbana (pp. 176-189). ARQ Ediciones.

Jirón, Paola; Mansilla, Pablo. (2013). "Atravesando la espesura de la ciudad: vida cotidiana y barreras de accesibilidad de los habitantes de la periferia urbana de Santiago de Chile". Revista de Geografía Norte Grande, (56), 53-74. http://dx.doi.org/10.4067/S0718$\underline{34022013000300004}$

Lapalma, Antonio Ismael. (2001). "El escenario de intervención comunitaria”. Revista de Psicología de Universidad de Chile, 10(2), 61-70. http://doi.org/10.5354/07190581.2001 .18573

Lefebvre, Henri. (2013 [1974]). Producción del espacio. Editorial Capitán Swing.

MASSEY, Doreen. (2012). Un sentido global del lugar. Icaria.

Segura, Ramiro. (2015). Vivir afuera. Antropología de la experiencia urbana. Editorial UnSAM.

SegurA, Ramiro. (2018). "La ciudad de los senderos que se bifurcan (y se entrelazan): centralidades conflictivas y circuitos segregados en una ciudad intermedia de la Argentina". Revista Universitas Humanistica, (85), 155-181.

Tamayo Sáez, M. (1997) "El análisis de las políticas públicas”. En Ernesto Carrillo Barroso y Rafael Bañón, La nueva Administración Pública (pp. 281-312). Alianza. 